NBER WORKING PAPER SERIES

ESTIMATING MODELS WITH

INTERTEMMPORAL SUBSTITUTION USING

AGGREGATE TIME SERIES DATA

Martin S. Eichenbaum

Lars Peter Hansen

Working Paper No. 2181

NATIONAL BUREAU OF ECONOMIC RESEARCH 1050 Massachusetts Avenue

Cambridge, MA 02138

March 1987

An earlier version of this research was presented at the National Bureau of Economic Research meetings on Economic Fluctuations, November 1983. This research was supported by grants from the National Science Foundation and the Sloan Foundation. Helpful comments were made by John Heaton, Joe Hotz, Dale Jorgenson,

Barbara Mace, Masao Ogaki, and Grace Tsaing. The research reported here is part of the NBER's research program in Economic Fluctuations Any opinions expressed are those of the authors and not those of the National Bureau of Economic Research. 


\section{Estimating Models with Intertemporal Substitution \\ Using Aggregate Time Series Data}

\section{ABSTRACT}

In conducting empirical investigations of the permanent income model of consumption and the consumption-based intertemporal asset pricing model, various authors have imposed restrictions on the nature of the substitutability of consumption across goods and over time. In this paper we suggest a method for testing some of these restrictions and present empirical results using this approach. Our empirical analyses focuses on three questions: (i) Can the services from durable and nondurable goods be treated as perfect substitutes? (ii) Are preferences completely separable between durable and nondurable goods? (iii) What is the nature of intertemporal substitutability of nondurable consumption? When consumers' preferences are assumed to be quadratic, there is very little evidence against the hypothesis that the services from durable goods and nondurable goods are perfect substitutes. These results call into question the practice of testing quadratic models of aggregate consumption using data on nondurables and services only. When we consider $S$ branch specifications, we find more evidence against perfect substitutability between service flows, but less evidence against strict separability across durable and nondurable consumption goods. Among other things, these findings suggest that the empirical shortcomings of the intertemporal asset pricing model cannot be attributed to the neglect of durable goods.

Mart in Eichenbaum

Graduate School of

Industrial Administration

Carnegie Mellon University

Pittsburgh, P.A. 15213
Lars Peter Hansen

Department of Economics

University of Chicago

Chicago, Il 60637 


\section{INTRODUCTION}

In conducting empirical investigations of the permanent income model of consumption and the consumption-based intertemporal asset pricing model, various authors have imposed restrictions on the nature of the substitutability of consumption across goods and over time. The purpose of this paper is to suggest a method for testing some of these restrictions and to present empirical results using this approach. Our empirical analysis focuses on three questions:

(i) Can the services from durable and nondurable consumption goods be treated as perfect substitutes?

(ii) Are preferences completely separable between durable and nondurable consumption goods?

(iii) What is the nature of intertemporal substitutability of nondurable consumption?

Several researchers have added the services from durables to nondurables to form a composite time series on consumption [e.g. see Darby (1975) and Sargent (1978)]. A justification for this practice is that the answer to question (i) is yes. Other researchers have ignored durables when studying models of aggregate consumption and asset returns [e.g. see Hall (1978), Flavin (1981), Grossman and Shiller (1981), and Hansen and Singleton (1982,1983)]. A justification for this practice is that the answer to question (ii) is yes. The third question is of interest because Sims (1980) and Novales (1986) have suggested that the usual practice of modeling nondurable consumption goods as being time separable may be inapproriate when studying the co-movements of consumption and interest rates. They argue that consumers may face adjustment costs in changing their consumption patterns as suggested by Houthakkar and Taylor (1970). A competing hypothesis is that what are classified as nondurable goods for measurement purposes have some degree of durability. 
To investigate these questions, we use a class of empirically tractable models of aggregate expenditures on consumption goods, relative prices, and asset returns. In the models we consider, consumers solve dynamic optimization problems subject to lifetime budget constraints. Real interest rates are allowed to vary over time. Since the consumers face an environment with uncertainty, they have incentives to trade assets other than riskless securities, e.g. equities. Some of the goods which consumers can purchase are durable. We follow Peck (1970) in modeling durable goods as assets that generate consumption services (dividends) in current as well as subsequent time periods. Consequently, intertemporal asset pricing theory can be used to deduce durable goods prices in the same way that the prices of equities paying dividends in current and future time perlods are deduced. The formal theoretical underpinnings of the models we consider are given in Eichenbaum, Hansen, and Richard (1984) and Hansen (1987). Those papers derive equilibrium relations between variables such as aggregate expenditures on goods, relative prices of goods, and prices of other securities. The resulting class of empirical models is sufficiently broad to encompass many of the empirical models that have been used to date.

In our empirical analysis, it is necessary to maintain a set of auxiliary assumptions. We maintain three types of assumptions: functional form restrictions on the preferences over service flows from consumption goods, functional form restrictions on the form of the nonseparabilities over time, and restrictions on growth in prices and aggregate quantities.

We use functional forms for consumers' preferences over service flows that satisfy two criteria. First, they rationalize the existence of a representative consumer in the sense of Gorman (1953). Second, they nest, as special cases, many of the preference specifications which have been used in the literature. The first criterion is imposed for tractability so that equilibrium prices do not depend on the initial distribution of resources among consumers in the economy. Furthermore, the three empirical questions of interest translate directly from properties of the preferences of the individual consumers to properties of the preferences of the corresponding representative consumer. 
We model nonseparabilities over time in preferences for consumption goods by viewing consumption goods as risk-free claims to consumption services in current and future time periods. Hence, consumption goods are intemporal bundles of consumption services. These goods are priced in terms of prices of the consumption service streams that they generate. Thus we are able to obtain convenient representations for the prices of newly acquired consumption goods. While this model of temporal nonseparabilities is admittedly extreme, it serves as an important benchmark for models in which utilization of durable goods is endogenized and/or private information and monitoring costs are introduced. Such extensions make the relation between the prices of consumer services and the purchase prices of consumption goods considerably more complicated. Consequently, our benchmark model has many computational advantages over these other models.

In this paper we abstract from modeling explicitly the production of new consumption goods. Instead, we allow for relatively general processes for equilibrium consumption. We do, however, take an explicit stand on the impact of economic growth and technological progress on the equilibrium prices and quantities. In so doing, it is important that we model growth in prices and quantities in a way that is internally consistent and allows for statistically consistent estimation of parameters governing substitution across goods and over time. We consider two specifications of growth that have been commonly used in applied time series analyses. One is a model in which geometric detrending induces stationarity, and the other is a model in which logarithmic differencing induces stationarity. Each of these approaches has some advantages and disadvantages. The first approach allows for more general specifications of preferences and service technologies. The second approach allows for additional forms of growth but can only be used for a smaller set of preferences and Gorman-Lancaster technologies. Both approaches imply a set of testable restrictions across the growth rates in quantities and prices.

As a practical matter, we can use only a limited array of prices on consumption goods and assets to estimate preference parameters and test restrictions. Conventional approaches used in consumer demand theory such as estimating demand functions are not applicable to our setting. 
Instead we follow an approach suggested by Hansen and Singleton (1982) and Hansen and Richard (1987). This approach restricts the preference shock process of the fictitious representative consumer and exploits conditional moment representations of equilibrium prices to obtain a set of unconditional moment restrictions. We then use the generalized method of moments (GMM) methodology as developed by Hansen (1982) to estimate preference parameters and test the over-identifying unconditional moment restrictions. This approach does not require a complete set of data on prices or a complete specification of the conditioning information used by consumers. On the other hand, as implemented in this paper, the approach does not permit unobservable time varying preference shocks for the representative consumer and does not account for time aggregation in prices and quantities.

The remainder of this paper is organized as follows. In section one we present a version of the theoretical model analyzed by Eichenbaum, Hansen, and Richard (1984) and Hansen (1987) and describe the equilibrium processes for economy-wide averages of the multiple consumption goods. In section two we display the equilibrium prices of claims to durable consumption goods and the implied restrictions on the growth rates of quantities and prices. In section three we show how to estimate parameters and test restrictions implied by the model. In section four we report empirical results obtained using quadratic preferences. In section five we report our empirical results using a version of the $S$ branch utility function suggested by Brown and Heien (1972). Finally, in section six we report our conclusions. 


\section{THE MODEL}

Eichenbaum, Hansen, and Richard (1984) analyzed an explicit equilibrium model with heterogeneous consumers and multiple durable consumption goods. They considered specifications of consumers' preferences and trading opportunities that rationalize the existence of a representative consumer in the sense of Gorman (1953). Consequently, their model implies econometrically tractable relations between aggregate consumption of durable goods, prices of durable goods, and asset returns. In this section we describe briefly a particular version of their economic model which accommodates growth.

\section{A. INFORMATION}

Consumers have a common sequence of information sets indexed by time. Let $I(t)$ denote the set of information available to consumers at time $t$. We assume that $I(t)$ is generated by $\{x(\tau): \tau \leq t\}$ where $x(t)$ is a state vector at time t.

\section{B. PREFERENCES}

The preferences of consumers for durable goods are defined in two stages. First, preferences are defined over a vector of consumption services. These preferences are separable over time and states. Then a dynamic GormanLancaster technology is defined that maps acquisitions of durable consumption goods into current and future consumption services.

Let $s^{j}(t)$ denote an m-dimensional vector of services, and $u^{j}(t)$ denote an $m$ dimensional vector of shocks to consumer $j$ 's preferences at time $t$. Both $s^{j}(t)$ and $u^{j}(t)$ are restricted to be in $I(t)$. At time zero, consumer $j$ ranks alternative consumption service processes using the utility function:

$$
(1 / \delta \sigma) E\left[\sum_{t=0}^{\infty} \beta^{t}\left\{U\left[s^{j}(t)-u^{j}(t)\right]^{\sigma}-1\right\} \mid I(0)\right]
$$

where $\delta=(1-\sigma)$ and 
(1.2) $U\left[s^{j}(t)-u^{j}(t)\right]=\left\{\sum_{i=1}^{m} \theta_{i}\left\{\delta\left[s_{i}^{j}(t)-u_{i}^{j}(t)\right]\right\}^{\alpha}\right\}^{1 / \alpha}$

The parameter $\beta$ is a subjective discount factor between zero and one and $\theta_{i}$ is nonnegative for each $i$. There are two branches of this utility function corresponding to whether $\sigma$ is less than or greater than one. When $\sigma$ is less than one, $\alpha$ is less than or equal to one and $u_{j}^{j}(t)$ can be viewed as a stochastic subsistence point of consumer $j$ for service $i$ at time $t$. On the other hand, when $\sigma$ is greater than one, $\alpha$ is greater than or equal to one and $u_{i}^{j}(t)$ can be viewed as a stochastic bliss point.

This specification of preferences is a version of the $S$ branch utility function. Brown and Heien (1972) proposed the $S$ branch utility function as a generalization of the linear expenditure system, and used these preferences to study consumption behavior in a certainty environment. This class of preferences has a number of special cases, some of which we focus on in our empirical analysis in section four. When $\sigma$ and $\alpha$ are the same, preferences are completely separable across the services in each time period and state. When $\sigma$ is less than one and $\alpha$ is zero, the function $U$ has the Cobb-Douglas form:

$$
U\left[s^{j}(t)-u^{j}(t)\right]=\prod_{i=1}^{m}\left\{\delta\left[s_{i}^{j}(t)-u_{i}^{j}(t)\right]\right\}^{\theta_{i}} .
$$

Finally, when both $\sigma$ and $\alpha$ are two, consumers' utility functions are quadratic.

Several authors have used special cases of these preferences in studying aggregate consumption behavior. For instance, Telser and Graves (1972), Hall (1978), Flavin (1981), and Mankiw (1982) use quadratic preferences in their empirical analyses. Grossman and Shiller (1981) and Hansen and Singleton $(1982,1983)$ use a single consumption good version $(m=1)$ and consider values of $\sigma$ that are less than one and subsistence points that are zero. Muellbauer (1981) uses a specification in which both $\sigma$ and $\alpha$ are zero so that preferences are logarithmically separable. Finally, Kydland and Prescott (1982) use preferences with $\sigma$ less than one and $\alpha$ equal to zero in which one of the consumption services depends on current and past leisure. 
Consumption goods are modeled as generating consumption services in current and future time periods. It is convenient to represent the intertemporal mapping from consumption goods into consumption services by introducing household capital stocks. Let $k^{j}(t-1)$ be a vector of household capital stocks of consumer $j$ which are brought into time $t$. At time $t$ consumer $j$ augments these stocks by a choice of $n$ consumption goods which we denote $c^{j}(t)$. The time $t$ vector of household capital is then given by

$$
k^{j}(t)=\Delta k^{j}(t-1)+\theta_{c}^{j}(t)
$$

for some matrices of real numbers $\Delta$ and $\Theta$. We restrict the matrix $\Delta$ to have eigenvalues that are strictly less than one in absolute value. The corresponding time $t$ consumption services are given by

$$
s^{j}(t)=\Gamma k^{j}(t) \text {. }
$$

for some matrix $\Gamma$. Relations (1.4) and (1.5) can be used to construct a process for consumption services $\left\{s^{j}(t): t=1,2, \ldots\right\}$ given an initial level $k^{j}(0)$ of the household capital stocks and a process for consumption goods $\left\{c^{j}(t): t=1,2, \ldots\right\}$. The matrices $\Delta, \Theta$, and $\Gamma$ are assumed to be common across all consumers.

This mapping from consumption goods into consumption services can be viewed as a dynamic version of the household technology suggested by Gorman (1980) and Lancaster (1966). More precisely, consumption goods are bundled claims to consumption services in current and future time periods since a vector of consumption goods $c(t)$ generates a vector of consumption services $\Gamma \Delta^{\tau} \Theta_{c}(t)$ at time $t+\tau$ for $\tau=0,1, \ldots$. Hence, the dynamic Gorman-Lancaster technology induces time nonseparabilities into consumers' indirect preferences for goods. This form of nonseparabilities is consistent with specifications used by Telser and Graves (1972) and Kydland and Prescott (1982).

One obvious rationale for (1.4) and (1.5) is that consumption goods are durable and are purchased in order to augment the stocks of household capital. In this case the matrix $\Delta$ dictates the rates at which the capital stocks depreciate. Specifications like (1.4) and (1.5) also appear in the consumer demand literature 
where the household capital stocks are introduced to accommodate habit formation, adjustment costs in consumption, or committed consumption expenditures [e.g. see Houthakker and Taylor (1970), Pollack (1970), and Boyce (1975)].

\section{EQUILIBRIUM CONSUMPTION PROCESS}

For convenience, we calculate equilibrium prices as if the economy were an endowment economy. The time $t$ vector of the $n$ economy-wide averages of new consumption goods is denoted $\mathrm{e}^{*}(\mathrm{t})$. The pricing relations we study also apply to economies in which new consumption goods are produced using intertemporal technologies with capital accumulation. For such economies $e^{*}(t)$ becomes the time $t$ average level of new consumption goods. The stochastic law of motion for $e^{*}(t)$ can be calculated by solving an optimal resource allocation (Pareto) problem. ${ }^{1}$

Historical time series data on aggregate consumption and relative prices display pronounced growth. This complicates both model specification and econometric estimation. Consistent estimation of substitution parameters is not feasible with arbitrary patterns of growth. A common strategy is to model growth so that there exist transformations for the time series data that induce stationarity. Such a strategy is adopted in this paper. Although we will not present a model in which growth is determined endogenously, we will be explicit about the growth processes that are accommodated. We consider models of growth that are consistent with two stationary-inducing transformations. The first transformation entails logarithmic detrending and the second entails taking ratios of variables (differencing logarithms). Each of these approaches has been used extensively in applied time series analysis, and for our purposes, each has some distinct advantages and disadvantages.

Suppose the economy-wide average consumption of each good grows geometrically over time. Let $\mu_{i}$ denote the growth rate in consumption good $i$ for $i=1,2, \ldots, n$. Then,

$$
e^{*}(t)=\Lambda(t) e(t)
$$


for $t \geq 0$ where $\Lambda(t)$ is a diagonal matrix with $\exp \left(\mu_{i} t+\phi_{i}\right)$ in the $i^{\text {th }}$ diagonal position, $e^{*}(t)$ is the vector of unscaled equilibrium consumption goods, and $e(t)$ is a vector of detrended equilibrium consumption goods with properties that will be specified subsequently. Taking logarithms of (1.6) gives

$$
\log \left[e^{*}(t)\right]=\phi+\mu t+\log [e(t)]
$$

where $\phi$ and $\mu$ are M-dimensional vectors with entries $\phi_{i}$ and $\mu_{i}$ in the $i^{\text {th }}$ position.

In our first model of growth, we assume that $e(t)$ is a component of the state vector $x(t)$, and the stochastic process $\{x(t):-\infty<t<+\infty\}$ is strictly stationary. The parameter $\phi$ is introduced for convenience so that

$$
E\{\log [e(t)]\}=0
$$

Given the assumption of stationarity, (1.8) holds for all time periods.

Suppose we take first differences of (1.7). Then

$$
\log \left[e^{*}(t)\right]-\log \left[e^{*}(t-1)\right]=\mu+\log [e(t)]-\log [e(t-1)]
$$

In our second model of growth we assume that $\log [e(t)]-\log [e(t-1)]$ is a component of $x(t)$ where again $\{x(t)-\infty<t<+\infty\}$ is a stationary stochastic process. The parameter $\mu$ is identified by assuming that

$$
E\{\log [e(t)]-\log [e(t-1)]\}=0 \text {. }
$$

The components of this process have deterministic growth rates given by the corresponding components of $\mu$, but the corresponding detrended process must now be treated differently to account for borderline nonstationarity in $\{\log [e(t)]: t \geq 0\}$. 


\section{EQUILIBRIUM SERVICE PROCESS}

To construct the economy-wide average level of consumption services in equilibrium, we let $g(0)$ be the economy-wide average detrended vector of household capital stocks brought into the initial time period zero. Using (1.4) and (1.5), we define recursively

$$
g(t)=\Delta g(t-1)+\Theta e(t)
$$

and

$$
f(t)=\Gamma g(t)
$$

for $t=1,2, \ldots$, where $\{f(t): t \geq 1\}$ is the detrended economy-wide average consumption service process and $\{g(t): t \geq 1\}$ is the detrended economy-wide average process for household capital. These latter two processes inherit any borderline nonstationarities in the equilibrium detrended consumption goods process.

The preference specifications (1.1) and (1.2) and the time-invariant household technology specification (1.4) and (1.5) are presumed to apply to detrended consumption goods and services. In appendix $A$ we describe specifications of preferences and household service technologies that are consistent with our analysis but apply to unscaled quantities. 


\section{EQUILIBRIUM PRICES}

Eichenbaum, Hansen, and Richard (1984) described alternative trading opportunities that in conjunction with the specification of consumers' preferences are sufficient to rationalize a representative consumer version of the economy described in section one. The preferences of the representative consumer are given by (1.1) with the average preference shock $u(t)$ replacing $u^{j}(t)$. In our analysis we assume that all uncertainty with respect to individual preference shocks is diversifiable. Hence we model $u(t)$ as a constant $u$ over time.

For our purposes, it is most convenient to suppose that there are markets in existence at some initial trading period for consumption services in each date and state. This does not imply that trading must take place in all of these markets to implement the equilibrium. Our focus is not on implementation but rather on the implied equilibrium prices. The introduction of markets in services (or attributes) as opposed to goods simplifies our calculation of equilibrium prices vis-a-vis standard analyses of static Gorman-Lancaster technologies.

Given a rich collection of markets and preferences that are time and state separable, consumers have no incentives to engage in additional trading in subsequent time periods. Nevertheless, the equilibrium prices of consumption services in the initial trading period imply shadow prices of claims to new and used consumption goods that clear hypothetical markets in an economy with sequential trading opportunities. In this section, we report the equilibrium shadow prices. The interested reader is referred to Eichenbaum, Hansen, and Richard (1984) for a formal derivation of these results.

In representing the equilibrium prices we proceed in two steps. First we abstract from growth in consumption and represent equilibrium prices as if $\{e(t)$ : $-\infty\langle t<+\infty\}$ is the economy-wide average consumption process. We then consider the implications of growth in the endowments for equilibrium prices. In particular, we use the equilibrium prices for the detrended quantities to deduce prices of the actual (unscaled) quantities. In this way growth in prices and quantities is modeled in a manner that is internally consistent. 
We first define the marginal utilities of a fictitious representative consumer and then use these marginal utilities to construct the equilibrium prices. The time $t$ marginal utility vector of the hypothetical representative consumer is $m u(t)=\left[m u_{1}(t), m u_{2}(t), \ldots, m u_{m}(t)\right]^{\prime}$ where

(2.1) $\quad m u_{i}(t)=\theta_{i}\left\{\delta\left[f_{i}(t)-u_{i}\right]\right\}^{\alpha-1}\left\{\sum_{i=1}^{m} \theta_{i}\left\{\delta\left[f_{i}(t)-u_{i}\right]\right\}^{\alpha}\right\}^{(\sigma-\alpha) / \alpha}$.

These marginal utilities define the equilibrium prices of the consumption services. Since consumption goods are just bundled claims to consumption services, we can use these marginal utilities to construct the prices of new consumption goods.

Let $\mathrm{q}(\mathrm{t})$ be the time $t$ relative spot price vector of new consumption goods, and let the first element of the new consumption goods vector at time $t$ be the numeraire. Then

$$
q(t)=\frac{E\left[\sum_{\tau=t}^{\infty} \beta^{\tau-t}\left(\Gamma \Delta^{\tau-t} \Theta\right)^{\prime} m u(\tau) \mid I(t)\right]}{E\left[\sum_{\tau=t}^{\infty} \beta^{\tau-t}\left(\Gamma \Delta^{\tau-t} \Theta h\right)^{\prime} m u(\tau) \mid I(t)\right]}
$$

where $h$ is a vector of zeroes except in the first position where there is a one. Notice that the numerator of the right-hand side of $(2.2)$ is the discounted consumption service flow generated by a vector of new consumption goods. Likewise, the denominator is the discounted service flow of the first new consumption good at time $t$. The marginal utility vector enters both the numerator and denominator as a stochastic discount factor.

Also, consider a security that pays off $y(t+1)$ units of the first new consumption good at time period $t+1$. The time $t$ relative price of this security, denoted $\pi[y(t+1), t]$, is given by 
(2.3)

$$
\pi[y(t+1), t]=\frac{E\left[y(t+1) \sum_{\tau=t+1} \beta^{\tau-t}\left(\Gamma \Delta^{\tau-t-1} \Theta h\right)^{\prime} m u(\tau) \mid I(t)\right]}{E\left[\sum_{\tau=t}^{\infty} \beta^{\tau-t}\left(\Gamma \Delta^{\tau-t} \Theta h\right)^{\prime} m u(\tau) \mid I(t)\right]}
$$

As in (2.2), the numerator and denominator of the right-hand side of (2.3) are discounted service flows.

We now use the equilibrium prices for the detrended quantites to deduce prices for the unscaled quantities. Let $q^{*}(t)$ be the vector of spot prices for the unscaled new consumption goods at time $t$. We take the first new unscaled consumption good at time $t$ to be the time $t$ numeraire. Then the relation between $q^{*}(t)$ and $q(t)$ is

$$
\log \left[q^{*}(t)\right]=\left(\phi_{1} 1-\phi\right)+\left(\mu_{1} 1-\mu\right) t+\log [q(t)]
$$

where 1 is an M-dimensional vector of ones and $q(t)$ is given by (2.2). In (2.4) the subtraction of $\phi+\mu t$ adjusts for the transformation of quantities given in (1.7) and the addition of $\mu_{1} t+\phi_{1}$ ensures that the first unscaled new consumption good is numeraire instead of the first detrended new consumption good. Similarly, let $y(t+1)$ be the payoff on a security expressed in units of the first unscaled consumption good, and let $\pi^{*}[y(t+1), t]$ be the time $t$ price of this security expressed in time $t$ units of the first unscaled consumption good. Then

$$
\begin{aligned}
\pi^{*}[y(t+1), t] & =\pi[y(t+1), t] \exp \left[(t+1) \mu_{1}+\phi_{1}-t \mu_{1}-\phi_{1}\right] \\
& =\pi[y(t+1), t] \exp \left(\mu_{1}\right)
\end{aligned}
$$

where $\pi[y(t+1), t]$ is given in (2.3).

If $e(t)$ and $y(t)$ are components of the vector $x(t)$ and $\{x(t):-\infty<t<+\infty\}$ is a stationary process, then the price processes $\{q(t):-\infty<t<+\infty\}$ and $\{\pi[y(t+1), t]$ : $-\infty<t<+\infty\}$ are jointly stationary with $\{x(t):-\infty<t<+\infty\}$. Since the process $\{q(t)$ : $-\infty<t<+\infty\}$ is stationary, (2.4) gives a set of stationary-inducing transformations for equilibrium relative prices. Hence there is a set of restrictions implied on the growth rates of prices and quantities. Among other things, these restrictions have the testable implication that expenditures on each consumption good grow at the same rate $\mu_{1}$. 
If instead, only $\log [e(t)]-\log [e(t-1)]$ and $y(t)$ are components of $x(t)$ where $\{x(t):-\infty\langle t<+\infty\}$ is a stationary process, then additional complications arise. While the economic model may still remain valid, in general there will not be a simple transformation, such as differencing logarithms of prices, that will induce stationarity. For particular parameterizations of our model, however, such differencing will in fact induce stationarity. Suppose $u$ is zero, $n=m, \alpha=$ 0 (so that $U$ is Cobb-Douglas), and that each consumption service is generated by a distinct consumption good so that $\Gamma \Delta^{\tau} \Theta$ is diagonal for all $\tau \geq 0$. In this case the ratios of equilibrium consumption services to the corresponding consumption goods are stationary. The equilibrium marginal utilities of consumption services are

$$
m u_{i}(t)=\theta_{i} U[f(t)]^{\sigma} / f_{i}(t)
$$

where $U$ is given by (1.3). Notice that $\log [m u(t)]$ can be expressed as a linear function of $\log [f(t)]$ plus a translation factor. It follows from (2.2) and (2.3) that $\left\{\log [q(t)]+\log [e(t)]-1 \log \left[e_{1}(t)\right]:-\infty\langle t<+\infty\}\right.$ and $\{\pi[y(t+1), t]:-\infty<t<+\infty\}$ are jointly stationary with $\{x(t):-\infty<t<+\infty\}$. Hence logarithmic differences of expenditures on each good relative to good one are jointly stationary. The same conclusions follow for the unscaled quantities and prices. Consequently, the vector of logarithms of consumption goods and relative prices are co-integrated as defined by Granger (1981).

In summary, our general strategy for accommodating growth is first to deduce time-invariant relations among quantities and prices. We then ask under what set of circumstances can these time-invariant relations be studied using detrended time series data. In appendix $A$ we describe a specification of technological progress in the mapping from unscaled goods to services that is consistent with our approach. Not suprisingly, for this specification to be valid one must impose a set of restrictions across the growth rates in equilibrium aggregate consumption and technological progress in the mapping from goods to services. 


\section{ECONOMETRIC ESTIMATION}

In this section we describe how to estimate the parameters of the model and test the over-identifying moment restrictions using GMM estimation met? First, we deduce a set of unconditional moment restrictions expressed in terms of the detrended data. Then we derive a corresponding set of equations involving the growth parameters and the unscaled data. Finally, we describe a method for estimating all of these parameters simultaneously and testing the unconditional moment restrictions.

\section{A. UNCONDITIONAL MOMENT RESTRICTIONS}

Relations (2.2) and (2.3) can be used to construct two sets of econometric equations. Using notation involving the forward shift or lead operator $F$, an alternative representation of $(2.2)$ is

$$
q(t) E\left\{\left[\Gamma(I-\beta \Delta)^{-1} \Theta h\right]^{\prime} m u(t) \mid I(t)\right\}-E\left\{\left[\Gamma(I-\beta \Delta)^{-1} \Theta\right]^{\prime} m u(t) \mid I(t)\right\}=0 .
$$

Removing conditional expectations, we obtain

$$
q(t)\left\{\left[\Gamma(I-\beta \Delta)^{-1} \Theta h\right]^{\prime} m u(t)\right\}-\left[\Gamma(I-\beta \Delta)^{-1} \Theta\right]^{\prime} m u(t)=w^{*}(t)
$$

where $E\left[w^{*}(t) \mid I(t)\right]=0$. Let $\zeta$ be a complex number with absolute value that is less than or equal to one. Then

$$
(I-\beta \Delta \zeta)^{-1}=\operatorname{adj}(I-\beta \Delta \zeta) / \operatorname{det}(I-\beta \Delta \zeta)
$$

where $\operatorname{adj}(\cdot)$ and $\operatorname{det}(\cdot)$ denote the adjoint and the determinant of the matrix argument respectively. Applying the scalar forward operator $\operatorname{det}(I-\beta \Delta F)$ to both sides of (3.2) gives

$$
\begin{gathered}
\operatorname{det}(I-\beta \Delta F)\left\{q(t)\left[\Gamma(I-\beta \Delta F)^{-1} \Theta h\right]^{\prime} m u(t)\right\}-[\Gamma \operatorname{adj}(I-\beta \Delta F) \Theta]^{\prime} \operatorname{mu}(t) \\
=w_{1}(t)
\end{gathered}
$$

where $E\left[w_{1}(t) \|(t)\right]=0$. The matrix function adj $(I-\beta \Delta \zeta)$ is always a finite 
order polynomial. We assume that the first consumption good only generates services in a finite number of time periods implying that $\left[\Gamma(I-\beta \Delta \zeta)^{-1} \Theta h\right]^{\prime}$ is also a finite-order polynomial. Consequently, equation (3.4) only depends on a finite number of future equilibrium marginal utility and price vectors. Also, the first equation in this system is trivial because the first consumption good is taken as numeraire. We omit this equation from our analysis.

Next, consider relation (2.3). Using lead operator notation, this equation can be expressed as

$$
\begin{aligned}
& \pi[y(t+1), t] E\left\{\left[\Gamma(I-\beta \Delta F)^{-1} \Theta h\right]^{\prime} m u(t) \| I(t)\right\} \\
&-\beta E\left\{y(t+1)\left[\Gamma(I-\beta \Delta F)^{-1} \Theta h\right]^{\prime} m u(t+1) \mid I(t)\right\}=0 .
\end{aligned}
$$

Thus, we have

$$
\begin{aligned}
\pi[y(t+1), t]\{[\Gamma(I & \left.\left.-\beta \Delta)^{-1} \Theta h\right]^{\prime} m u(t)\right\} \\
& -\beta\left\{y(t+1)\left[\Gamma(I-\beta \Delta F)^{-1} \Theta h\right]^{\prime} m u(t+1)\right\}=w_{2}(t) .
\end{aligned}
$$

where $E\left[w_{2}(t) \mid I(t)\right]=0$.

It is convenient for us to think of (3.4) and (3.6) as a system of econometric equations with an extensive set of cross-equation restrictions. The composite vector $w(t)=\left[w_{1}(t)^{\prime}, w_{2}(t)\right]^{\prime}$ can be viewed as the disturbance vector which satisfies

\section{(3.7) $\quad E[w(t) \mid I(t)]=0$.}

Hence $w(t)^{\prime}$ 'is a multi-period forecast error. Relation (3.7) is a conditional moment restriction implied by our theoretical model. To study the econometric implications, it is convenient to replace the conditional moment restriction by a corresponding unconditional moment restriction. Let $z(t)$ be a matrix of variables in $I(t)$ that is conformable with $w(t)$ such that $z(t) w(t)$ have a finite absolute first moment. Then by the Law of Iterated Expectations, (3.7) implies that 
(3.8) $E[z(t) w(t)]=0$.

We assume the process $\{z(t):-\infty<t<+\infty\}$ is jointly stationary with $\{x(t)$ : $-\infty<t<+\infty\}$. Then the parameters of the model can be estimated using time series versions of the GMM estimators suggested by Hansen (1982). A necessary condition for identification is that the number of free parameters does not exceed the number of rows of $z(t)$. When the number of rows of $z(t)$ exceeds the number of free parameters, the model is over-identified so that there are additional moment restrictions that can be tested. Hansen describes a procedure for testing these restrictions.

The estimation approach suggested by Hansen is not directly applicable because the equilibrium marginal utility vectors for consumption services depend on the initial specification of the economy-wide capital $g(0)$. In many circumstances, this initial vector depends on the entire past history of economywide averages of new consumption goods. When the admissible parameters determining $\Delta$ are constrained so that the eigenvalues of $\Delta$ are strictly less than $1-\epsilon$ in absolute value for some pre-specified positive $\epsilon$, the asymptotic inferences are not sensitive to misspecification of $g(0)$. On the other hand, more accurate guesses for $\mathrm{g}(0)$ will probably result in higher quality asymptotic approximations. In our empirical analysis, we use other data sources to obtain an approximation for $g(0)$.

\section{B. PARAMETER ESTIMATION IN THE PRESENCE OF GROWTH}

When growth is present in the time series data, relations (1.7) and (2.4) can be used to deduce estimation equations for the parameters $\mu$ and $\phi$. The expectation of the logarithm of the detrended quantities has mean zero by construction, but the expectation of the detrended price is not necessarily zero. We introduce an additional vector of parameters to accommodate this latter nonzero expectation. The two blocks of equations we add to our system are:

$$
\log \left[e^{*}(t)\right]=\phi+\mu t+\log [e(t)]
$$

and 


$$
\log \left[q^{*}(t)\right]=\phi^{+}+\left(\mu_{1} 1-\mu\right) t+(\log [q(t)]-E\{\log [q(t)]\})
$$

where $\log [e(t)]$ and $\{\log [q(t)]-E\{\log [q(t)]\}$ are now treated as unobservable and $\phi^{+}=E\{\log [q(t)]\}$. The first equation in $(3.10)$ is trivial because the first consumption good is used as numeraire. Consequently, this equation is removed from the block. Notice that the parameter vector $\mu$ enters equation blocks (3.9) and (3.10). This cross-equation restriction is by itself testable, and we report results of such a test in section four.

Equation systems (3.9) and (3.10) can be estimated using least squares. For us it is convenient to use GMM estimation since the remaining econometric relations are estimated using this estimation methodology. Let $v(t)$ contain $\log [e(t)]$ and the nontrivial components of $\log [q(t)]-E\{\log [q(t)]\}$. Then

$$
E\left[(1, t / T)^{\prime} \otimes v(t)\right]=0
$$

The choice of $T$ in (3.11) is equal to the sample size. Heuristically, we can think of $(1, t / T)$ as a vector of instrumental variables to be used in estimating $\mu, \phi$, and $\phi^{+}$. The division of $t$ by $T$ is done so that the resulting variable behaves more like a stationary process.

We are interested in studying unconditional moment restrictions (3.8) and (3.11) simultaneously. Hansen (1986) provides a set of sufficient conditions for the composite vector

$$
\left\{(1 / T)^{\frac{1}{2}} \sum_{t=1}^{T}\left[\begin{array}{r}
(1, t / T)^{\prime} \otimes v(t) \\
z(t) w(t)
\end{array}\right]: T \geq 1\right\}
$$

to converge in distribution to a normally distributed random vector with mean zero and covariance matrix $\Omega$ where $\Omega$ is partitioned as:

(3.13) $\Omega=\left[\begin{array}{ll}\Omega_{11} & \Omega_{12} \\ \Omega_{21} & \Omega_{22}\end{array}\right]$. 
The partitions of $\Omega$ can be expressed as the following limits:

(3.14) $\Omega_{11}=\left[\begin{array}{cc}1 & 1 / 2 \\ 1 / 2 & 1 / 3\end{array}\right] \otimes \lim _{l \rightarrow \infty} \sum_{\ell=-l}^{l}[(l-|\tau|) / l] E\left[v(t) v(t-\tau)^{\prime}\right]$

$$
\Omega_{12}=\left[\begin{array}{l}
1 \\
1 / 2
\end{array}\right] \otimes \lim _{l \rightarrow \infty} \sum_{\tau=-l}^{l}[(l-|\tau|) / l] E\left[v(t) w(t-\tau)^{\prime} z(t-\tau)^{\prime}\right]
$$

and

$$
\Omega_{22}=\lim _{l \rightarrow \infty} \sum_{\tau=-1}^{l}\{(l-|\tau|) / l] E\left[z(t) w(t) w(t-\tau)^{\prime} z(t-\tau)^{\prime}\right]
$$

The limiting (asymptotic) covariance matrix $\Omega$ in (3.13) is assumed to be nonsingular.

It turns out that the limits in (3.15) and (3.16) simplify substantially. Since the disturbance term process $\{w(t):-\infty<t<+\infty\}$ is a process of multiperiod forecast errors conditioned on current (time $t$ ) information, all but a finite number of terms in the sums in (3.15) and (3.16) are zero. The number of nonzero terms is determined by the length of the forecast horizon.

Let $p_{0}$ denote the vector of parameters which we seek to estimate. This vector contains the preference parameters for consumption services, the parameters of the matrices $\Delta, \Theta, \Gamma$, and the growth parameters $\phi, \phi^{+}$, and $\mu$. Given a hypothetical value of the parameter vector, we can construct an approximation to the vector

$$
\left[\begin{array}{c}
(1, t / T)^{\prime} \otimes v(t) \\
z(t) w(t)
\end{array}\right]
$$

The only reason this approximation may not be exact is that the initial conditions for the household capital stocks may not be known a priori. The parameter vector $p_{0}$ is not known a priori but is restricted to be in an admissible parameter space $P$. Let $h_{T}(t, p)$ be the approximating function for any $p$ in $P$. Define

$$
g_{T}(p)=(1 / T)^{\frac{1}{2}} \sum_{t=1}^{T} h_{T}(t, p)
$$


Under appropriate regularity conditions, $\left\{g_{T}\left(p_{0}\right): T \geq 1\right\}$ has the same asymptotic distribution as the sequence in (3.12) [see Hansen (1986)]. We then estimate $p$ using a GMM estimator that minimizes:

\section{(3.19) $\quad g_{T}(p)^{\prime} W_{T} g_{T}(p)$}

by choice of $p$ in $P$. The sequence $\left\{W_{T}: T \geq 1\right\}$ of distance matrices converges almost surely to a positive definite matrix of real numbers.

There is great flexibility in the choice of the sequence of distance matrices. It turns out sequences which converge almost surely to $\Omega^{-1}$ result in GMM estimators with the smallest asymptotic covariance matrix among the class of GMM estimators that minimize quadratic forms like (3.19). Furthermore, the sequence of minimized values of such asymptotically optimal GMM estimators, denoted $\left\{J_{T}: T \geq 1\right\}$, converges in distribution to a chi-square distributed random variable with degrees of freedom equal to the difference between the total number of unconditional moment restrictions and the number of coordinates of $p$. Hence $J_{T}$ can be used to test the over-identifying moment restrictions.

To implement this procedure, one must estimate $\Omega$ consistently. This can be accomplished in the following two steps. First obtain an initial estimate $\rho_{T}$ for $p_{0}$ using some nonsingular specification for $W_{T}$. Then form the sample counterparts to the terms in (3.14) - (3.16) using $h_{T}\left(t, \rho_{T}\right)$ to approximate the vector given in (3.17). Appropriate zero restrictions should be imposed, and a choice of $l$ considerably less than $T$ should be used to obtain an estimate of $\Omega$ [e.g. see Newey and West (1987)]. In practice, it is a good idea to check for sensitivity with respect to $l$ since the asymptotic theory provides very little guidance for choosing $\ell$.

The questions posed in the introduction to this paper can be translated into restrictions on the parameter vector $p_{0}$. These restrictions can be tested by taking the difference between the minimized value of objective (3.19) when the restrictions are imposed and the minimized value of the objective when the restrictions are not imposed. The same distance matrix should be used for both runs. This matrix should be a consistent estimate of $\Omega^{-1}$ even when the restrictions are not satisfied. The resulting test statistic, which we denote $R_{T}$, 
is distributed asymptotically as a chi-square random variable with degrees of freedom equal to the number of restrictions that are being tested. This test is an analogue to the one suggested by Gallant and Jorgenson (1979) for examining parameter restrictions using nonlinear three-stage least squares estimation.

In sections one and two we described a second model of growth. For this model we consider the following alternative set of equations to estimate $\mu$ :

$$
v(t)=\log \left[e^{*}(t)\right]-\log \left[e^{*}(t-1)\right]-\mu
$$

where $E[v(t)]=0$ is used in place of (3.11). The parameters $\phi$ and $\phi^{+}$are normalized to be zero. Then estimation and inference can be conducted as before except that expressions (3.14) and (3.15) are modified to be

$$
\Omega_{11}=\lim _{l \rightarrow \infty} \sum_{\tau=-l}^{l}[(l-|\tau|) / \ell] E\left[v(t) \vee(t-\tau)^{\prime}\right]
$$

and

$$
\Omega_{12}=\lim _{l \rightarrow \infty} \sum_{\tau=-l}^{l}[(l-|\tau|) / l] E\left[v(t) w(t-\tau)^{\prime} z(t-\tau)^{\prime}\right]
$$

There is one additional complication that arises in this second model of growth. The matrix $\Omega_{11}$ given in (3.21) is zero if the first model is the appropriate one for any of the individual equilibrium consumption processes. In this case the corresponding estimated growth rates should be imposed as if they were the true rates, and the corresponding equations in (3.20) should be removed from the system. A similar strategy can be employed if the vector process $\{e(t): t \geq 1\}$ is co-integrated. 


\section{QUADRATIC PREFERENCES}

Several researchers have used quadratic preferences to analyze permanent income models of consumption, e.g. Hall (1978), Flavin (1981), Mankiw (1982), Bernanke (1985), and Novales (1985). In this section we consider the questions posed in the introduction when preferences are quadratic $(\sigma=\alpha=2)$, and there are two consumption goods $(n=2)$. Although we used data on nondurables and services for one good and durables for the other good, to avoid confusion we refer to the first good as nondurables rather than nondurables and services. Associated with these goods is a four-dimensional vector of household services. The matrices $\Delta$ and $\Theta$ are parameterized as

$$
\Delta=\left[\begin{array}{llll}
0 & 0 & 0 & 0 \\
\delta_{1} & 0 & 0 & 0 \\
0 & 0 & \delta_{2} & 0 \\
0 & 0 & 1 & 0
\end{array}\right] \quad \Theta=\left[\begin{array}{ll}
1 & 0 \\
0 & 0 \\
0 & 1 \\
0 & 0
\end{array}\right]
$$

The first household capital stock is nondurable consumption, and the second household capital stock is the one period lag of nondurable consumption scaled by a depreciation parameter $\delta_{1}$. The third household capital stock is the stock of durable goods, and the fourth stock is the one period lag of the stock of durable goods. The stock of durable goods depreciates by a factor $\delta_{2}$ and the second consumption good is the new addition to this stock.

We assume that there are three consumption services obtained from the four household capital stocks. The matrix $\Gamma$ governing this transformation is given by

$$
\Gamma=\left[\begin{array}{rrrr}
1 & 1 & \gamma & 0 \\
0 & 0 & 1 & 0 \\
0 & 0 & 1 & -1
\end{array}\right]
$$

Specification (4.2) implies that the first service can be obtained from any of the first three household capital stocks. The parameter $\gamma$ dictates the substitutibility between the capital stocks obtained from durable and nondurable consumption goods. The second service can only be obtained from the stock of durable goods. The third service is the change in the stock of durable goods. 
The ideal or bliss level for this third service is assumed to be zero so that, when combined with a quadratic preference specification, this service captures adjustment costs in durable goods.

The interpretation of the parameter $\delta_{1}$ as capturing depreciation relies on $\delta_{1}$ being positive. When $\gamma$ is zero and there are costs to adjusting nondurables, $\delta_{1}$ will be negative. ${ }^{2}$ Sims (1980) and Novales (1985) have suggested that such adjustment costs might be important in explaining co-movements of nominal interest rates and real economic variables.

As for the parameters governing preferences over consumption services, we imposed the normalization that $\theta_{1} u_{1}=1$ and estimated the pariinuicurs, $\theta_{1}, \theta_{2}$, $\theta_{3}, \nu=\theta_{2} \mathrm{u}_{2}$, and $\beta$. This parameterization allows the preferences to be linear in the services when either $\theta_{1}$ or $\theta_{2}$ is zero.

Since the second service is the stock of durable goods, we used estimates from Musgrave (1979) as initial conditions for this service. Given this initial condition, an initial observation on nondurables, and hypothetical parameters of the Gorman-Lancaster technology, we can construct a time series for equilibrium consumption services as suggested in section three.

In reporting our empirical results, we show how much the objective function used in estimation increases when various interesting restrictions are imposed on the parameters of the model. As we indicated in section three, the increase in the objective function can be used as a formal statistic to test restrictions on the parameters. We considered three hypotheses pertaining to the substitutability of consumption across goods and over time. Each of these hypotheses can be represented as a set of restrictions on the parameters of preferences and the household service technology.

The first hypothesis is

$H_{1}: \quad \theta_{3}=0$

Under this hypothesis there are no adjustment costs in changing the stock of durables. Bernanke (1985) has suggested that such adjustment costs in consumption of durables might be present. 
The second hypothesis is

$H_{2}: \quad \theta_{2}=\theta_{3}=\nu=0$.

Under this hypothesis there is a single consumption service so that the services from durables and nondurables are perfect substitutes and can be aggregated. In this case movements in the relative price of durable goods reflect movements in the implicit term structure of risk-free interest rates for the single consumption service. The practice of aggregating the services from durables and nondurables to form a composite time series on aggregate consumption can be justified under this hypothesis. Such procedures have been used, for example, by Darby (1975) and Sargent (1978).

The third hypothesis is

$\mathrm{H}_{3}: \quad \theta_{3}=\gamma=0$.

Under this hypothesis there are two consumption services, each depending on a single consumption good. Hence, preferences are separable across durable and nondurable goods. If this hypothesis were true, then intertemporal marginal rates of substitution for nondurables would not depend on the level of durables. The practice of ignoring durables in testing the relationship between aggregate consumption and asset returns often can be rationalized by this hypothesis. Examples of papers which abstract from durable goods when studying quadratic models of aggregate consumption and asset returns include Hall (1978) and Flavin (1981).

To estimate parameters and test restrictions, we used aggregate time series data on purchases of nondurable goods plus services, durable goods, and the relative price of new durable goods as measures of $e_{1}^{*}(t), e_{2}^{*}(t)$ and $q_{2}{ }^{*}(t)$ respectively. The two quantity series were measured by monthly, seasonally adjusted real aggregate purchases of nondurable goods plus services, and durable goods for the time period 1959:1 through 1978:12. ${ }^{3}$ A time series on relative prices was constructed by dividing the implicit price deflator for nondurable goods and services by the implicit price deflator for new durable goods. These data were obtained from the CITIBASE data tape. In addition, we used one-month 
returns on Treasury Bills for a security payoff. Hence, $y(t+1)$ is the ex post real return on one-month Treasury Bills, and $\pi[y(t+1), t]$ is one for all $t$. The time series of Treasury Bill yields were taken from Ibbotson and Sinquefeld (1979). Nominal returns were converted to real returns using the implicit price deflator for nondurables and services. We terminated our time series at the end of 1978 because of the change in operating procedures of the Federal Reserve Bank in 1979.

The matrix $z(t)$ was chosen to be

$$
z(t)=\left[\begin{array}{ll}
1 & 0 \\
0 & 1
\end{array}\right] \otimes\left[\begin{array}{l}
1 \\
e(t) \\
e_{1}(t-1) \\
q_{2}(t) \\
y(t)
\end{array}\right]
$$

Hence, $z(t)$ is dimensioned twelve by two, and $g_{T}$ has eighteen components.

The results from estimating the parameters of the model are presented in Table 4.1 as the base run. ${ }^{4}$ The estimated values of $\theta_{2}, \theta_{3}$, and $\nu$ are all small relative to their standard errors and have incorrect signs. This suggests that hypotheses $\mathrm{H}_{1}$ and $\mathrm{H}_{2}$ may be empirically plausible. The $J_{T}$ statistic indicates that there is definite evidence against the over-identifying restrictions, but the evidence is not overwhelming.

Table 4.1 also reports results obtained from testing hypotheses $\mathrm{H}_{1}, \mathrm{H}_{2}$, and $H_{3}$. According to the $R_{T}$ statistics, there is very little evidence against hypotheses $\mathrm{H}_{1}$ and $\mathrm{H}_{2}$ while there is a substantial amount of evidence against hypothesis $\mathrm{H}_{3}$. Also, the estimates of $\delta_{1}$ are consistently around .5 implying there is some degree of durability in goods classified as nondurable, and no adjustment costs. 
TABLE 4.1

$$
\sigma=\alpha=2
$$

$\begin{array}{lcccc}\text { Parameters* } & \text { Base } & \mathrm{H}_{1} & \mathrm{H}_{2} & \mathrm{H}_{3} \\ \beta & .994 & .994 & 1.010 & 1.005 \\ \theta_{1} \times 10^{3} & (.007) & (.007) & (.007) & (.001) \\ & 6.01 & 6.07 & 5.72 & 6.61 \\ \theta_{2} \times 10^{5} & (9.29) & (.23) & (.21) & (.29) \\ & -.84 & -.79 & 0.00 & -.12 \\ \theta_{3} \times 10^{5} & (1.18) & (.99) & -\cdots & (.10) \\ & -1.40 & 0.00 & 0.00 & 5.87 \\ \delta_{1} \times 10 & (3.09) & -\cdots & -\cdots & (4.43) \\ \delta_{2} \times 10 & 4.87 & 4.74 & 5.37 & 2.67 \\ & (.72) & (.52) & (.41) & (.40) \\ \gamma \times 10^{3} & 9.78 & 9.77 & 9.83 & 9.90 \\ & (.04) & (.04) & (.05) & (.04) \\ \nu \times 10^{5} & 5.64 & 5.59 & 5.37 & 0.00 \\ & (.68) & (.61) & (.41) & -7 . \\ \mu_{1} \times 10^{3} & -3.45 & -3.24 & 0.0 & 2.06 \\ & (5.32) & (4.38) & --. & (3.72) \\ \mu_{2} \times 10^{3} & 2.80 & 2.80 & 2.80 & 2.82 \\ & (.04) & (.04) & (.05) & (.04) \\ \mathrm{J}_{\mathrm{T}}^{* *} & 4.37 & 4.37 & 4.37 & 4.33 \\ \mathrm{R}_{\mathrm{T}}^{* *} & (.09) & (.09) & (.09) & (.07) \\ & 17.54 & 17.65 & 20.63 & 33.57 \\ & (.996) & (.993) & (.992) & (1.00) \\ & --- & .11 & 3.09 & 16.03 \\ & & (.260) & (.622) & (1.00)\end{array}$

*asymptotic standard errors in parentheses

** confidence levels in parentheses 
Table 4.2 reports additional results pertaining to hypothesis $\mathrm{H}_{2}$. Under this hypothesis the services from durables and nondurables are perfect substitutes. The only difference between the base run in Table 4.2 and the $H_{1}$ run in Table 4.1 , is that the weighting matrix $W_{T}$ for the base run in Table 4.2 was estimated imposing all of the restrictions implied by $\mathrm{H}_{2}$. Given our estimates of the parameters of the Gorman-Lancaster technology, durables produce on average $13 \%$ of the first consumption service. Also, the estimated value of $\theta_{1}$ is sufficiently small that the esimated marginal utilities for the first consumption service are positive for all time periods in the sample.

To investigate the impact of trend estimation on our analysis, we estimated the parameters of the model under the presumption that the trend estimates in the base run are equal to the true trend parameters and that these parameters are known a priori. The resulting estimates and estimated standard errors are reported in Table 4.2. Note that for some of the parameters, the estimated standard errors are notably reduced so that trend estimation can have an important impact on inference.

Table 4.2 also reports results pertaining to the timing convention used to align the consumption and return data. In analyzing discrete time models there is an element of arbitrariness in how the data matches the model. Initially, we used the same timing convention as Hansen and Singleton (1982, 1983). They assume that in making consumption decisions in a given month, consumers know their end-of-month returns on assets and have access to the proceeds from these returns. In this paper we also considered an alternative convention in which consumers are presumed only to know and have access to the returns from the previous month in making consumption decisions. In the first timing convention, consumption is viewed as an end-of-month decision while in the second timing convention, consumption is viewed as a beginning-of-month decision. 5 The results from estimating the model under the second timing convention are reported in Table 4.2. As can be seen, the choice of timing convention has little effect on our results. 
28

TABLE 4.2

$$
\begin{gathered}
\sigma=\alpha=2 \\
\theta_{2}=\theta_{3}=\nu=0
\end{gathered}
$$

Parameters*

Base

$\beta$

$\theta_{1} \times 10^{3}$

$\delta_{1} \times 10$

$\delta_{2} \times 10$

$\gamma \times 10^{3}$

$\mu_{1} \times 10^{3}$

$\mu_{2} \times 10^{3}$

$J_{T}^{* *}$
1.010

(.008)

5.40

(.10)

6.18

(.22)

9.79

(.03)

4.86

(.81)

2.80

(.08)

4.39

(.08)

19.77

(.989)
No Trend

Estimation

1.010

(.007)

5.40

(.06)

6.18

(.14)

9.79

(.03)

4.86

(.77)

$\cdots$

$--$

13.68

(.942)
Alternative Timing

1.012 (.008)

5.28

(.09)

6.49

(.22)

9.78

(.03)

5.34

(.94)

2.80 (.08)

4.37

(.08)

22.43

(.996)

*asymptotic standard errors in parentheses.

** confidence levels in parentheses. 
In Table 4.3 we report the results from estimating the model under hypothesis $\mathrm{H}_{2}$ when two asset pricing equations were studied simultaneously. Let $y_{1}(t+1)$ and $y_{2}(t+1)$ denote the ex post real returns on one-month Treasury Bills and a value-weighted index of stocks on the New York Stock Exchange, respectively. The time series of stock returns was taken from the CRSP (Center for Research in Securities Prices) data tapes. The matrix $z(t)$ was chosen to be

$$
z(t)=\left[\begin{array}{lll}
z_{1}(t) & 0 & 0 \\
0 & z_{2}(t) & 0 \\
0 & 0 & z_{2}(t)
\end{array}\right]
$$

where $z_{1}(t)^{\prime}=\left[1, q_{2}(t)\right]$ and $z_{2}(t)^{\prime}=\left[1, q_{2}(t), e(t)^{\prime}, y_{1}(t), y_{2}(t)\right]$. Hence $z(t)$ is dimensioned fourteen by three, and $g_{T}$ has twenty components. The results are reported in Table 4.3 and are quite similar to those reported in the first column of Table 4.2. The function value is somewhat higher as might be expected since more orthogonality conditions are used in the estimation procedure. 
TABLE 4.3

MULTIPLE ASSETS

$$
\sigma=\alpha=2
$$

$$
\begin{aligned}
& \text { Parameters* } \\
& \beta \\
& \theta_{1} \times 10^{3} \\
& \delta \times 10 \\
& \delta_{2} \times 10 \\
& \gamma \times 10^{3} \\
& \mu_{1} \times 10^{3} \\
& \mu_{2} \times 10^{3} \\
& J_{T}^{* *}
\end{aligned}
$$

Estimates

1.009

(.010)

5.63

(.17)

5.32

(.53)

9.75

(.04)

6.25

(.95)

2.81

$(.04)$

4.36

(.09)

25.13

(.995)

*asymptotic standard errors in parentheses.

${ }^{* *}$ confidence levels in parenthesis. 
To study the role of nonseparability across consumption goods in the asset pricing equations, we eliminated the relative price equations from the system of econometric equations. Consequently, two unconditional moment restrictions were removed from consideration. We found it to be very difficult to estimate both $\delta_{2}$ and $\gamma$ in this case. In fact when $\gamma$ is zero, $\delta_{2}$ ceases to be identified in the reduced equation system. Recall that preferences over consumption acquisitions are strictly separable when $\gamma$ is zero. For this reason we imposed the constraint that $\delta_{2}$ be .975 , considered a range of values for $\gamma$, and estimated the remaining parameters. This constraint on $\delta_{2}$ is consistent with the results reported in Table 4.3.

In Table 4.4 we report values of the criterion function used in estimation for several specifications of $\gamma$. The values of $\gamma$ ranged from the point estimate reported in Table 4.3 to zero. Notice that the drop in the criterion function over the range of $\gamma$ specifications is only 1.69. A chi-square statistic of this magnitude with one degree of freedom has a confidence level of .81 . This indicates that the introduction of durable goods into the subset of econometric equations involving asset prices does not reduce the criterion function very dramatically.

TABLE 4.4

MULTIPLE ASSETS

$$
\begin{aligned}
& \sigma=\alpha=2 \\
& \delta_{2}=.975
\end{aligned}
$$

$\begin{array}{llllllll}\text { Values of } \gamma \times 10^{3} & 6.25 & 5.00 & 4.00 & 3.00 & 2.00 & 1.00 & 0.00\end{array}$ Function Values $\begin{array}{lllllll}24.05 & 24.11 & 24.25 & 24.44 & 24.75 & 25.18 & 25.74\end{array}$ 
Finally, we report evidence regarding the restrictions on the growth rates of quantities and prices. Recall that the first block of six unconditional moment restrictions depends only on the five parameters $\mu_{1}, \mu_{2}, \mu_{1}-\mu_{2}, \phi^{+}$, and the two parameters of $\phi$. Consequently, these five parameters can be estimated separately. Furthermore, these six moment restrictions are the source of one of the over-identifying restrictions that were tested using the $J_{T}$ test statistic. It is of interest to examine these six moment conditions in isolation.

In Table 4.5 we report the constrained estimates of $\mu_{1}, \mu_{2}$ and $\mu_{1}-\mu_{2}$. using only these six orthogonality restrictions. In addition, we report the unconstrained estimates obtained by relaxing the restriction that the growth rate in relative prices equals $\mu_{1}-\mu_{2}$. The $J_{T}$ statistic provides some evidence against the restrictions on the growth rates, but the evidence is not overwhelming. This is consistent with the results reported in Table 4.2 indicating that there is more evidence against the over-identifying restrictions when trend estimation is taken into account. ${ }^{6}$

\section{TABLE 4.5}

INFERENCE ON GROWTH RATES

Parameters*

Constrained

Unconstrained

$\mu_{1} \times 10^{3}$

$\mu_{2} \times 10^{3}$

$\left(\mu_{1}-\mu_{2}\right) \times 10^{3}$

$\mathrm{J}_{\mathrm{T}}^{* *}$

*standard errors are in parentheses.

** probability values of test statistics are in parentheses. 
Summarizing the results in this section, we found a high degree of substitutability between nondurable goods and the services from the stock of durable goods. Also, we found that goods which are classified as nondurable generate service flows which extend beyond the purchase date in monthly data. On the other hand, we found very little evidence in support of adjustment costs in either the stock of durable goods or in nondurable goods. All of these results were obtained under the maintained assumption that the preferences of consumers are quadratic. In the next section we investigate these empirical hypotheses using other specifications of preferences. 


\section{S BRANCH PREFERENCES}

In this section we consider results obtained when $\sigma$ is estimated although constrained to be less than one. The household technology is modified from that used in section four by eliminating the fourth capital stock and the third service and setting the parameter $\gamma$ to zero. Hence $n$ and $m$ are both two. The matrices $\Delta, \Theta$, and $\Gamma$ are parameterized as

$$
\Delta=\left[\begin{array}{lll}
0 & 0 & 0 \\
\delta_{1} & 0 & 0 \\
0 & 0 & \delta_{2}
\end{array}\right] \quad \Theta=\left[\begin{array}{ll}
1 & 0 \\
0 & 0 \\
0 & 1
\end{array}\right] \quad \Gamma=\left[\begin{array}{lll}
1 & 1 & 0 \\
0 & 0 & 1
\end{array}\right]
$$

Although $\gamma$ is zero, $\alpha$ is no longer required to be equal to $\sigma$. Hence, in this specification, $\alpha$ dictates the substitutability between the services from durable and nondurable consumption goods. Finally, the economy-wide average subsistence point $u$ is set to zero, and the preference parameters $\theta_{1}$ and $\theta_{2}$ are normalized so that their sum is one.

We report results pertaining to four hypotheses. The first hypothesis is

$$
H_{1}: \alpha=0
$$

Under this hypothesis the function $U$ used in representing preferences for consumption services has the Cobb-Douglas form given by (1.3).

The second hypothesis is

$H_{2}: \alpha=1$.

Under this hypothesis the services from durables and nondurables are perfect substitutes. This hypothesis is the analogue to the second hypothesis in section four.

The third hypothesis is

$H_{3}: \alpha=\sigma$. 
Under this hypothesis the implied preferences for consumption goods are strictly separable across durable and nondurable consumption goods. This hypothesis is the analogue to the third hypothesis in section four and was maintained by Grossman and Shiller (1981) and Hansen and Singleton (1982, 1983).

The fourth hypothesis is

$\mathrm{H}_{4}: \sigma=\alpha=0$

Under this hypothesis preferences are logarithmically separable over the two consumption services as was assumed by Muellbauer (1981).

In our empirical analysis, we transformed the original econometric equations as follows. We formed $w_{1}{ }^{+}(t)=w_{1}(t) / m u_{2}(t)$ and $w_{2}{ }^{+}(t)=w_{2}(t) / m u_{1}(t)$. Since $m u_{1}(t)$ and $m u_{2}(t)$ are in $I(t), E\left[w_{1}{ }^{+}(t) \mid I(t)\right]=0$ and $E\left[w_{2}{ }^{+}(t) \mid I(t)\right]=0$. Hence the unconditional moment restriction

$$
E\left[z(t) w^{+}(t)\right]=0
$$

is satisfied where $z(t)$ is a matrix comfortable to $w^{+}(t)$ with elements that are in $I(t)$ such that $\left|z(t) w^{+}(t)\right|$ has a finite expectation. This transformation of equations accomplishes two things. First, each of the resulting equations has a constant term that is normalized to unity. Second, the resulting econometric equations are expressed in terms of marginal rates of substitution for consumption services rather than marginal utilities. This latter feature guarantees that our econometric equations can be expressed in terms of ratios of consumption services. This feature is particularly convenient for the special case in which $\alpha$ is zero (Cobb-Douglas) as we will see subsequently.

The model was estimated using the procedures described in section three and the data described in section four. The results are presented in Table 5.1 as the base run. The estimated standard errors of $\sigma$ and $\alpha$ are sufficiently large relative to the respective point estimates to indicate that each of the hypotheses $\mathrm{H}_{1}, \mathrm{H}_{2}$, and $\mathrm{H}_{4}$ may be empirically plausible. Also, the estimated standard error of $\theta_{1}$ is quite large relative to its point estimate. The estimate of the 
parameter governing depreciation in nondurables $\left(\delta_{1}\right)$ is positive and large relative to its standard error implying that nondurable consumption goods generate consumption services in time periods subsequent to their acquisition. The point estimate of the parameter governing depreciation in durables $\left(\delta_{2}\right)$ is the same as was obtained when preferences were assumed to be quadratic (see Table 4.1). The estimate of the discount factor $(\beta)$ exceeds one reflecting the low ex post returns to holding Treasury Bills during our sample period. Finally, the $\mathrm{J}_{T}$ statistic is somewhat lower than the corresponding statistic for the base quadratic run. ${ }^{7}$ There is still, however, some evidence against the overidentifying restrictions. 
TABLE 5.1

$$
\begin{aligned}
& \sigma<1 \\
& \alpha \leq 1
\end{aligned}
$$

$\begin{array}{lccccc}\text { Parameters* } & \text { Base } & \mathrm{H}_{1} & \mathrm{H}_{2} & \mathrm{H}_{3} & \mathrm{H}_{4} \\ \beta & 1.003 & 1.003 & 1.003 & 1.003 & 1.003 \\ \sigma & (.001) & (.001) & (.001) & (.001) & (.001) \\ \alpha & .62 & .54 & .54 & .41 & 0 \\ \alpha & (.28) & (.26) & (.28) & (.21) & \\ \theta_{1} \times 10 & -.90 & 0 & 1 & .41 & 0 \\ \delta_{1} \times 10 & (.96) & & (.24) & (.28) & \\ & 2.11 & 8.70 & 9.96 & 9.63 & 8.73 \\ \delta_{2} \times 10 & (5.78) & (.06) & (.01) & (.29) & (.05) \\ & 2.44 & 2.30 & 2.07 & 2.56 & 3.11 \\ \mu_{1} \times 10^{3} & (.77) & (.81) & (1.15) & (.69) & (.36) \\ & 9.78 & 9.75 & 9.77 & 9.72 & 9.75 \\ \mu_{2} \times 10^{3} & (.02) & (.04) & (.06) & (.07) & (.04) \\ & 2.74 & 2.76 & 2.77 & 2.76 & 2.72 \\ \mathrm{~J}_{\mathrm{T}}^{* *} & (.04) & (.03) & (.04) & (.04) & (.03) \\ \mathrm{R}_{\mathrm{T}}^{* *} & 4.31 & 4.34 & 4.37 & 4.35 & 4.27 \\ & (.08) & (.07) & (.07) & (.06) & (.07) \\ & 15.77 & 16.16 & 21.36 & 17.39 & 20.29 \\ & (.973) & (.960) & (.994) & (.974) & (.984) \\ & & .39 & 5.59 & 1.62 & 4.52 \\ & & (.468) & (.982) & (.800) & (.896) \\ & & & & & \end{array}$

*asymptotic standard errors in parentheses.

** confidence levels in parentheses. 
Table 5.1 also reports our results from testing hypotheses $H_{1}$ through $H_{4}$. According to the reported $R_{T}$ statistics, there is very little evidence against hypothesis $H_{1}$ and only weak evidence against hypotheses $H_{3}$ and $H_{4}$. Of the four hypotheses, $\mathrm{H}_{2}$ appears to be the least plausible empirically.

It is of interest to compare the results of the hypothesis tests reported in Tables 5.1 to those in 4.1. Overall, there is somewhat less evidence against the over-identifying restrictions when $\sigma$ is estimated (although constrained to be less than one) than when preferences are assumed to be quadratic $(\sigma=2)$. Also, there is more evidence against the perfect substitutability hypothesis $\left(\mathrm{H}_{2}\right)$ and less evidence against the strict separability hypothesis $\left(\mathrm{H}_{3}\right)$.

All of the empirical results discussed so far correspond to the first of the two models of growth discussed in sections one and two. We now examine the empirical plausibility of these two models. In Table 5.2 we report results from estimating regressions of $\log \left[e_{1}^{*}(t)\right], \log \left[e_{2}{ }^{*}(t)\right]$, and $\log \left[q_{2}{ }^{*}(t)\right]$ onto a constant, a time trend, and one lag of the respective variable. Under the first model of growth, the coefficients on the lag of the variables should have absolute values that are less than one. The estimates of the asymptotic standard errors that are reported in the parentheses were calculated under the presumption that the first model of growth is the appropriate model. Under the second model of growth, the coefficient on the time trend should be zero and the coefficient on the lag of the variable should be one. Dickey and Fuller (1981) deduced the asymptotic distribution of the likelihood ratio test when the disturbance terms in the regression are normal independent random variables and the second model of economic growth is the appropriate model. Let $I_{T}$ denote the likelihood ratio test statistic suggested by Dickey and Fuller (1981). Phillips and Peron (1985) showed how to modify the test statistic to accomodate more general distributional assumptions while preserving the same asymptotic distribution that was tabulated by Dickey and Fuller (1981). In particular, Phillips and Peron allowed for more general forms of serial dependence and conditional heteroskedasticity in the disturbance term. Let $\mathcal{I}_{\mathrm{T}}{ }^{*}$ denote the modification of the likelihood ratio statistic suggested by Phillips and Peron. ${ }^{8}$ 
TABLE 5.2

\section{TESTS FOR UNIT ROOTS}

Right-hand-side variable Nondurables and Services Durables Relative Prices

Constant

$$
0.15
$$

(0.03)

0.004

$(0.004)$

Time Trend $\times 10^{4}$

1.26

(0.35)

4.32

(1.08)

$-0.36$

(0.26)

Lag

0.96

(0.01)

0.91

(0.02)

0.98

(0.02)

$I_{T}$

2.65

5.50

2.00

$I_{T}^{*}$

2.60

6.15

2.72

*asymptotic standard errors in parentheses

Dickey and Fuller (1981) reported critical values for their test statistic of about 5.4 for confidence level .9 and 6.3 for confidence level .95 . Hence the time series on durable goods is the only one for which there is much evidence against the second model of growth. Even for this series, the evidence is not overwhelming. Dickey and Fuller also indicated that the likelihood ratio test does not have very much power against many alternatives that are speclal cases of our first model of growth. Consequently, the results in Table 5.2 indicate that it is very difficult to discriminate between the two models of growth suggested in section one using the data set we considered. For this reason, we also report results for the second model of growth. A cost of using this model is that our statistical methods are applicable only under hypothesis $H_{1}(\alpha=0)$. 
To estimate the parameters under $H_{1}$ and the second model of growth, we chose the matrix $z(t)$ to be

$$
z(t)=\left[\begin{array}{ll}
1 & 0 \\
0 & 1
\end{array}\right] \otimes\left[\begin{array}{l}
e_{1}^{*}(t) / e_{1}^{*}(t-1) \\
e_{2}^{*}(t) / e_{2}^{*}(t-1) \\
q_{2}^{*}(t) e_{2}^{*}(t) / e_{1}^{*}(t) \\
y(t) \\
1
\end{array}\right] .
$$

Thus, we imposed ten unconditional moment restrictions to estimate the five parameters $\beta, \sigma, \theta_{1}, \delta_{1}$, and $\delta_{2}$. Our estimation results are reported in Table 5.3 under the column heading Single Asset. The estimation equations for the asset return and the relative price are identical with those used to obtain the results in Table 5.1 under the column $H_{1}$. Not suprisingly, the point estimates reported in these two columns are very similar. There is some difference in the estimated standard errors because of differences in the estimation equations for the growth parameters and in the choice of the matrix $z(t)$. For instance, the estimate of $\sigma$ in Table 5.3 is again about .5 although the estimated standard error is larger than in Table 5.1. The estimate of $\delta_{1}$ in Table 5.3 is again positive but is estimated with less precision than in Table 5.1. The estimates of $\theta_{1}$ and $\delta_{2}$ are very close to those reported in Table 5.1, but the corresponding estimated standard errors are smaller.

Table 5.3 also reports results from estimating the model when two asset pricing equations were considered simultaneously. Let $y_{1}(t+1)$ and $y_{2}(t+1)$ denote the ex post returns on one-month Treasury Bills and a value-weighted index of stocks on the New York Stock Exchange. The matrix $z(t)$ was chosen to be

$$
z(t)=\left[\begin{array}{lll}
1 & 0 & 0 \\
0 & 1 & 0 \\
0 & 0 & 1
\end{array}\right] \otimes\left[\begin{array}{l}
e_{1}{ }^{*}(t) / e_{1}{ }^{*}(t-1) \\
y_{1}(t) \\
y_{2}(t) \\
1
\end{array}\right]
$$


TABLE 5.3

$$
\begin{aligned}
& \sigma<1 \\
& \alpha=0
\end{aligned}
$$

\section{Preferences*}

$\beta$

$\sigma$

$\theta_{1} \times 10$

$\delta_{1} \times 10$

$\delta_{2} \times 10$

$\mu_{1} \times 10^{3}$

$\mu_{2} \times 10^{3}$

$J_{T}^{* *}$
Single Asset

.999

(.004)

$-.51$

(.61)

8.63

(.02)

3.06

(1.59)

9.70

(.05)

2.95

(.22)

5.55

1.19

8.35

(.862)
Multiple Assets

1.005

(.003)

$-.36$

(.55)

8.62

(.03)

3.80

(.55)

9.71

(.030)

2.99

(.19)

4.67

(1.23)

19.14

(.992)

*standard errors in parentheses.

** probability values of test statistic.

Thus we imposed twelve unconditional moment restrictions. The results are reported under the column Multiple Assets. 
The point estimates in this case are very similar to those obtained using only one asset return. As in Hansen and Singleton (1982), however, there is substantially more evidence against the model when two asset returns are used. This is not surprising because we found very little evidence against the hypothesis that preferences are logarithmically separable. 


\section{CONCLUSIONS}

In this paper we presented a set of empirical results pertaining to inter- and intratemporal substitutability of consumption goods. The results in section four indicate that when preferences are constrained to be quadratic, there is very little evidence against the hypothesis that the services from durable goods and nondurable goods are perfect substitutes. This finding supports the practice of aggregating these services into a single service. On the other hand, this finding is inconsistent with the existence of constant real interest rates because prices of durable goods relative to nondurable goods are not constant over time. In addition, these results call into question the practice of testing quadratic models of aggregate consumption using data on nondurables and services only.

The finding of perfect substitutability between service flows of these different consumption goods is admittedly extreme and possibly sensitive to the specification of preferences. For this reason, we reported results using $S$ branch preference specifications. The results in section five show that for $S$ branch prefence specifications, there is more evidence against perfect substitutability between service flows, but less evidence against strict separability across durable and nondurable consumption goods. Among other things, these findings suggest that the empirical shortcomings of the intertemporal asset pricing model cannot be attributed to the neglect of durable goods.

For both specifications of preferences, we found that goods classified as nondurable goods generate positive consumption services in subsequent time periods. Since this finding may be sensitive to aggregation-over-time biases, it would be of interest to examine this hypothesis using a model in which consumers make decisions more frequently than once a month and the consumption data are viewed as monthly averages over finer intervals of time.

The models we considered in this paper are important benchmarks for models with endogenous depreciation, private information, and/or lumpiness in the acquisition of durable goods. Deducing testable implications from models with these alternative features will be a challenging but possibly fruitful task. We hope that by documenting the empirical shortcomings of the benchmark models, we have made this task a little easier. 


\section{NOTES}

1 For our analysis, it is convenient to view economies with capital accumulation as being in a suitably defined stochastic steady state. Alternatively, one could use a model for which suitably transformed values of consumption and capital goods converge to a stochastic steady state starting from arbitrary initial conditions. Often, the rate or convergence to the stochastic steady state is sufficiently fast so that the initial conditions do not effect the asymptotic distribution of the econometric estimators.

2 This follows from the analysis in Hansen (1987) where it is shown that there are multiple ways to represent quadratic preferences when there are more services than goods. In particular, it is shown that the preferences can always be represented equivalently with the same number of services as goods but with a different Gorman-Lancaster technology.

${ }^{3}$ The use of seasonally adjusted data is potentially problematic since our theoretical model provides no rationale for such adjustments. Miron (1986) has studied the impact of seasonal adjustment of consumption in models similar to those considered here.

${ }^{4}$ The results reported in all tables except 5.2 , used a value of $l=15$ to estimate $\Omega$. Also, we continued using previous round parameter estimates $p_{t}$ to obtain $e$ eeew estimates of $\Omega$ until the probability value of $J_{T}$ statistic did not change in the third decimal place.

5 The examination of the timing convention is not a substitute for investigating the effects of aggregation-over-time-biases that might occur. For instance, aggregation-over-time-biases can occur if consumers make consumption decisions continuously and an econometrician's time series data is the total consumption over an interval of time. Such biases can easily distort estimates of intertemporal substitution parameters such as $\delta_{1}$. In this paper we maintain the assumption that consumption decisions are made monthly. 
${ }^{6}$ Bernanke (1985) studied the behavior of consumption of nondurables and services and durables by assuming that the growth rate in both series were the same as the growth rate in GNP. His assumption is clearly incompatible with the results in Table 4.5 .

7 The minimized values of the criterion functions reported in Tables 4.1 and 5.1 are not directly comparable because the form of the estimation equations is different and because the restrictions on preferences across these two tables are not nested. In principle, one could estimate a preference specification for consumption services that nests both of the preference specifications used in Tables 4.1 and 5.1. Such a nesting is given in section one. Most likely, the resulting criterion function used in such an estimation would not be very well behaved. The results in both Tables 4.1 and 5.1 confirm that unless additional restrictions are imposed, it is difficult to estimate all of the preference parameters. Non-nested testing procedures such as those suggested by Cox (1961) require that more structure be imposed on the estimation problem than we have imposed here.

${ }^{8}$ To Implement the Phillips-Peron test, one must estimate a limit like that given on the right-hand side of (3.14). We found some sensitivity of the estimated standard errors and the $I_{\tau}^{*}$ statistic to the choice of $l$, although this sensitivity was never sufficient to reverse conclusions. The results reported in Table 5.2 take $l$ to be 20 . 


\section{APPENDIX A}

In this appendix we present specifications of preferences and services technologies that are consistent with our modeling of growth in prices and quantities.

Consider first the service technology. Let $k^{* j}(t)$ denote the vector of unscaled household capital stocks of person $j$, and $c^{* j}(t)$ denote the vector of unscaled new consumption goods of person $j$. The unscaled counterpart to (1.4) is

$$
\text { (A. 1) } \quad k^{* j}(t)=\Delta^{*} k^{* j}(t-1)+\Theta^{*}(t) c^{* j}(t)
$$

where $\Delta^{*}=\exp \left(\mu_{s}\right) \Delta$ and $\Theta^{*}(t)=\exp \left(\mu_{s} t\right) \Theta \Lambda(t)^{-1}$. We use (1.5) to map the household capital stock into consumption services. The matrix function $\Theta^{*}(t)$ governs the technological progress in this mapping. Equation (A.1) is designed so that

$$
\text { (A.2) } \quad f^{*}(t)=\Gamma g^{*}(t)=\exp \left(\mu_{s} t\right) f(t)
$$

where $\left\{f^{*}(t): t \geq 1\right\}$ and $\left\{g^{*}(t): t \geq 1\right\}$ are the economy-wide unscaled average processes on consumption services and household capital. Hence an implication of this technology in conjunction with our assumption about the growth in equilibrium acquisitions of new consumption goods is that the equilibrium growth rate in consumption services is $\mu_{s}$ for all services.

Next, we consider specifications of preferences. When equilibrium consumption grows over time and $\sigma$ is greater than one, it is necessary for the preference shocks to grow over time to avoid the implication that consumers become satiated. Similarly, when $\sigma$ is less than one, it is necessary for preference shocks to grow in order for the impact of the subsistence levels not to diminish over time. Thus, to allow for growth in services we transform the preference shock processes for each individual. Let $u^{j *}(t) \equiv u^{j}(t) \exp \left(t \mu_{s}\right)$, so that the growth rate in the preference shocks is the same as the growth rate in the equilibrium consumption service vector. Also, define $\beta^{*} \equiv \exp \left(-\mu_{s} \sigma\right) \beta$. Then the preferences over unscaled consumption services are given by (1.1) and (1.2) with $s^{j *}(t), u^{j *}(t)$, and $\beta^{*}$ replacing $s^{j}(t), u^{j}(t)$, and $\beta$ respectively. 
47

It is easy to verify that this specification of preferences and service technology rationalizes our treatment of growth in prices and new consumption goods. Notice that there is a restriction linking the growth rates in equilibrium aggregate consumption and technological progress in the Gorman-Lancaster technology. This restriction is not deduced from more primitive assumptions but is simply posited. On the other hand, this restriction has empirical content and can be tested.

The growth rate $\mu_{s}$ and the discount factor $\beta^{*}$ are left unidentified in our analysis because direct observations are not available for consumption services. These parameters must satisfy particular inequality restrictions, however. For instance, $\beta^{*}$ is less than one, and

(A.3) $\mu_{s}>\log (\beta) / \sigma \quad$ for $\sigma>0$

(A.4) $\mu_{s}<\log (\beta) / \sigma$ for $\sigma<0$. 


\section{REFERENCES}

Bernanke, B.S., "Adjustment Costs, Durables, and Aggregate Consumption," Journal of Monetary Economics, Vol 15 (1985) 41-68.

Boyce, R., "Estimation of Dynamic Gorman Polar Form Utility Functions," Annals of Economic and Social Measurement, 4:1 (1975), 103-116.

Brown, M.J., and D. Heien, "The S-Branch Utility Tree: A Generalization of the Linear Expenditure System," Econometrica, 40 (1972) 737-747.

Cox, D.R., "Tests of Separate Families of Hypotheses," Proceedings of the Fourth Berkeley Symposium in Mathematical Statistics and Probability, University of California Press (1961) 105-123.

Darby, M.R., "Post War US Consumption, Consumer Expenditures, and Savings," American Economic Review, Papers and Proceedings, 65 (1975) 217-222.

Dickey, D.A. and W.A. Fuller, "Distribution of the Estimators for Autoregressive Time Series with a Unit Root," Econometrica, 49, (1981) 1057-1072.

Eichenbaum, M.S., L.P. Hansen, and S.F. Richard, "The Dynamic Equilibrium Pricing of Durable Consumption Goods," manuscript (1984).

Flavin, M.A., "The Adjustment of Consumption to Changing Expectations About Future Income," Journal of Political_Economy, 89 (1981) 9741009

Gallant, A.R., and D.W. Jorgenson, "Statistical Inference for a System of Simultaneous, Nonlinear, Implicit Equations in the Context of Instrumental Variable Estimation," Journal of Econometrics 11 (1979) 275-302.

Gorman, W.M., "Community Preference Fields," Econometrica (1953) 6380.

Gorman, W.M., "A Possible Procedure for Analyzing Quality Differentials in the Egg Market," Review of Economic Studies 47 (1980) 843-856. 
Granger, C.W.J., "Some Properties of Time Series Data and Their Use in Econometric Model Specification," Journal of Econometrics, (1981) 121 130.

Grossman, S.J., and R.J. Shiller, "The Determinants of the Variability of Stock Market Prices," American Economic Review 71 (1981) 222-227. Hall, R.E., "Stochastic Implications of the Life Cycle-Permanent Income Hypothesis: Theory and Evidence," Journal of Political Economy 86 (1978) 971-987.

Hansen, L.P., "Large Sample Properties of Generalized Method of Moments Estimators," Econometrica 50 (1982) 1029-1054.

, "Lecture Notes on Time Series Econometrics," manuscript $(1986)$.

, "Calculating Asset Prices in Three Example Economies," (forthcoming in Ed. T.F. Bewley, Advances in Econometrics, Fifth World Congress, 1987).

, and S.F. Richard, "The Role of Conditioning Information in Deducing Testable Restrictions Implied by Dynamic Asset Pricing Models," (forthcoming in Econometrica, 1987).

, and K.J. Singleton, "Generalized Instrumental Variables Estimation of Nonlinear Rational Models," Econometrica 50 (1982) 1269-1286.

, "Stochastic Consumption, Risk Aversion,

and the Temporal Behavior of Asset Returns," Journal of Political Economy $91: 1$ (1983) 249-265.

Houthakker, H.S. and L.D. Taylor, Consumer Demand in the United States 1929-1970, 2nd Edition, Harvard University Press, Cambridge, MA (1970).

Ibbotson, R.G., and R.A. Sinquefeld, Stocks, Bonds, Bills, and Inflation: Historical Returns, 1926-1978, 2nd. ed. Charlottesville, VA: Financial Analysts Res. Found. (1979). 
Kydland, F.E., and E.F. Prescott, "Time to Build and Aggregate Fluctuations," Econometrica 50 (November 1982) 1345-1370.

Lancaster, K., "A New Approach to Consumer Theory," Journal of Political. Economy 74 (1966) 132-157.

Mankiw, N.G., "Hall's Consumption Hypothesis and Durable Goods," Journal of Monetary Economics 10 (1982) 417-425.

Miron, Jeffrey A., "Seasonal Fluctuations and the Life Cycle-Permanent Income Model of Consumption," J.P.E., 94:6 (1986) 1258-79.

Muellbauer, J., "Testing Neoclassical Models of the Demand for Consumer Durables," Theory and Measurement of Consumer Behavior, A. Deaton (ed.), New York: Cambridge University Press (1981).

Musgrave, J.C., "Durable Goods Owned by Consumers in the United States, 1925-1977," Survey of Current Business (March 1979).

Newey, W., and K.D. West, "A Simple, Positive Definite, Heteroskedasticity and Autocorrelation Covariance Matrix," (forthcoming in Econometrica 1987).

Novales, A., "A Stochastic, Monetary Equilibrium Model of the Interest Rate," manuscript, SUNY at Stony Brook (1985).

Peck, S.C., "The Individual's Choice of Goods, Assets and Durables," Second World Congress of the Econometric Society paper (1970).

Phillips, P.C.B. and P. Perron, "Testing for a Unit Root in Time Series Regression," mimeo (1986).

Pollak, R.A., "Habit Formation and Dynamic Demand Functions," Journal of Political Economy, 78, (1970) pp. 745-763.

Sargent, T.J., "Rational Expectations, Econometric Exogeneity, and Consumption," Journal of Political Economy 86:4 (1978) 673-700.

Sims, C.A., "International Evidence on Monetary Factors in Macroeconomic Fluctuations," manuscript (1980).

Telser, L.G., and R.J. Graves, Functional Analysis in Mathematical Economics. Chicago: University of Chicago Press (1972). 